\title{
The Promotive Effects of Antioxidative Apigenin on the Bioavailability of Paclitaxel for Oral Delivery in Rats
}

\author{
Sang-Joon $\mathrm{CHOI}^{1}$, and Jun-Shik $\mathrm{CHOI}^{2, *}$ \\ ${ }^{1}$ College of Medicine, ${ }^{2}$ College of Pharmacy, Chosun University, Gwangju 501-759, Republic of Korea
}

(Received August 14, 2010; Revised September 30, 2010; Accepted October 12, 2010)

\begin{abstract}
This study was to investigate the effect of apigenin on the bioavailability of paclitaxel after oral and intravenous administration in rats. The effect of apigenin on P-glycoprotein (P-gp), cytochrome P450 (CYP)3A4 activity was evaluated. The pharmacokinetic parameters of paclitaxel were determined in rats after oral $(40 \mathrm{mg} / \mathrm{kg})$ or intravenous $(5 \mathrm{mg} / \mathrm{kg})$ administration of paclitaxel with apigenin $(0.4,2$ and $8 \mathrm{mg} / \mathrm{kg})$ to rats. Apigenin inhibited CYP3A4 activity with $50 \%$ inhibition concentration $\left(\mathrm{IC}_{50}\right)$ of $1.8 \mu \mathrm{M}$. In addition, apigenin significantly inhibited P-gp activity. Compared to the control group, apigenin significantly increased the area under the plasma concentration-time curve (AUC, $p<0.05$ by $2 \mathrm{mg} / \mathrm{kg}, 59.0 \%$ higher; $p<0.01$ by 8 $\mathrm{mg} / \mathrm{kg}, 87 \%$ higher) of oral paclitaxel. Apigenin also significantly ( $p<0.05$ by $2 \mathrm{mg} / \mathrm{kg}, 37.2 \%$ higher; $p<0.01$ by $8 \mathrm{mg} / \mathrm{kg}, 59.3 \%$ higher) increased the peak plasma concentration $\left(\mathrm{C}_{\max }\right)$ of oral paclitaxel. Apigenin significantly increased the terminal half-life $\left(\mathrm{t}_{1 / 2}, p<0.05\right.$ by $\left.8 \mathrm{mg} / \mathrm{kg}, 34.5 \%\right)$ of oral paclitaxel. Consequently, the absolute bioavailability (A.B.) of paclitaxel was significantly ( $p<0.05$ by $2 \mathrm{mg} / \mathrm{kg}, p<0.01$ by $8 \mathrm{mg} / \mathrm{kg}$ ) increased by apigenin compared to that in the control group, and the relative bioavailability (R.B.) of oral paclitaxel was increased by 1.14- to 1.87 -fold. The pharmacokinetics of intravenous paclitaxel were not affected by the concurrent use of apigenin in contrast to the oral administration of paclitaxel. Accordingly, the enhanced oral bioavailability by apigenin may be mainly due to increased intestinal absorption caused via P-gp inhibition by apigenin rather than to reduced renal and hepatic elimination of paclitaxel. The increase in the oral bioavailability might be mainly attributed to enhanced absorption in the gastrointestinal tract via the inhibition of P-gp and reduced first-pass metabolism of paclitaxel via the inhibition of the CYP3A subfamily in the small intestine and/or in the liver by apigenin. It appears that the development of oral paclitaxel preparations as a combination therapy is possible, which will be more convenient than the i.v. dosage form.
\end{abstract}

Keywords: Apigenin, Paclitaxal, Bioavailability, Pharmacokinetics, CYP3A4, P-gp, Rats

\section{INTRODUCTION}

Paclitaxel $\left(\right.$ Taxol $^{\mathbb{R}}$ ), an antineoplastic agent widely used in the treatment of breast and ovarian cancer, is derived from the bark of the Pacific yew tree (Taxus brevifolia) (Wani et al., 1971). Paclitaxel is primarily metabolized in the liver by CYP 3A4 and 2C8 and undergoes biliary excretion (Harris et al., 1994; Rahman et al., 1994; Sonnichsen et al., 1995). The fecal excretion in humans approximates $70 \%$ of the administered paclitaxel dose, with $6 \alpha$-hydroxypaclitaxel being the major metabolite (Walle et al., 1995). The low bioavailability of oral paclitaxel, which

*Corresponding author

Tel: +82-62-230-6365 Fax: +82-62-222-5414

E-mail: jsachoi@chosun.ac.kr presents a major therapeutic problem, is caused by poor solubility and first-pass metabolism, which occurs in the liver and in the small intestine. Therefore, paclitaxel is dissolved in a mixture of polyoxyethyleneglycerol triricinoleate 35 (Cremophor EL) and dehydrated ethanol (1:1, v/v) for the intravenous (IV) dosage form. However, cremophor EL is itself toxic and causes vasodilatation, labored breathing, lethargy and hypotension when administered intravenously (Rowinsky et al., 1993). Paclitaxel is a substrate for P-glycoprotein (P-gp) efflux in intestinal cells. P-gp is a member of the ATP-binding cassette (ABC) superfamily (Sparreboom et al., 1997). The low bioavailability of paclitaxel following oral administration results from metabolism by enzymes or counter-transport processes caused by $\mathrm{P}$-gp in the intestinal wall. There have been some attempts 
to improve the oral delivery of paclitaxel via the inhibition of P-gp and metabolic enzymes. For example, several studies have reported that the bioavailability of oral paclitaxel was markedly higher when taken in combination with cyclosporin $A$ and verapamil as a P-gp and CYP $3 A$ inhibitors than after oral paclitaxel alone in human (Berg et al., 1995; van Asperen et al., 1998; Meerum Terwogt et al., 1999; Choi and $\mathrm{Li}, 2005)$. But their usefulness is limited because they can result in cardiac toxicity (Choi et al., 1997).

Flavonoids represent a group of phytochemicals that are produced by various plants in high quantities (Dixon and Steele, 1999). Among the flavonoids, apigenin ( $4^{\prime}, 5,7-$ trihydroxyflavone) is present in citrus fruits and guava and exhibits various biological activities including antioxidative, anti-mutagenic, anti-inflammatory, anti-tumor, anti-inflammatory and anti-cancer effects (Galati et al., 2001; Nafisi et al., 2008; Yin et al., 2008; Chuang et al., 2009; Gates et al., 2009; Jeong et al., 2009). Furthermore, apigenin is reported to interact with CYP3A4 as well as the P-gp efflux pump (Critchfield et al., 1994; Fukuda et al., 1997; Ho et al., 2001). Nguyen et al. (2003) reported that apigenin significantly increased the cellular accumulation of vinblastine, a P-gp substrate in Panc-1 cells. Ho et al. (2001) reported very weak inhibitory effect of apigenin on CYP3A4 mediated metabolism but others recently reported a potent inhibitory effect of apigenin against CYP3A4 activity (Kimura et al., 2010). Therefore, the effect of apigenin on the inhibition of CYP enzyme activity is inconclusive. Hence, we attempted to re-evaluate the inhibition potency of apigenin on CYP3A4 and P-gp activity using CYP inhibition assay and rhodamine-123 retention assay in MCF-7/ ADR cells overexpressing P-gp.

There are a few papers regarding the effects of some flavonoids on the bioavailability of paclitaxel in rats (Choi et al., 2004; Choi and Shin, 2005; Choi et al., 2006). Apigenin is expected to change the bioavailability and pharmacokinetics of drugs that are substrates of P-gp and/or CYP3A4, if they are used concomitantly. Apigenin and paclitaxel could be sometimes prescribed as a combination therapy for the treatment or prevention of cancer. However, the possible effects of apigenin, a flavonoid, on the bioavailability of paclitaxel, a substrate of P-glycoprotein (P-gp) and CYP3A4, have not been reported in vivo. Therefore, the aim of this study was to investigate the effects of apigenin, an antioxidant, on the CYP3A4, P-gp activity and bioavailability of paclitaxel for oral drug delivery in rats.

\section{MATERIALS AND METHODS}

\section{Materials}

Paclitaxel was purchased from Bristol-Myers Squibb Co. (NY, USA). Saline $(0.9 \% \mathrm{NaCl}$ injectable solution) was obtained from Choongwae Co. (Seoul, Korea), and acetonitrile, methanol and tert-butylmethylether were acquired from Merck Co. (Darmstadt, Germany). Apigenin and nbutyl p-hydroxybenzoate (butyl paraben) were purchased from Sigma Chemical Co. (St. Louis, MO, USA) and phosphoric acid from Junsei Co. (Tokyo, Japan). All other chemicals for this study were reagent grade and were used without further purification.

A high performance liquid chromatography (HPLC, Waters 1515 isocratic HPLC Pump, Waters 717 plus autosampler, Waters 2487 Dual $\lambda$ absorbance detector, Waters Co., Milford, MA, USA), sonicator (Bransonic Ultrasonic, CT, USA), MG 2100 Eyela dry thermo bath (Rikakikai Co., Tokyo, Japan), high-speed micro centrifuge (Hitachi Co., Tokyo, Japan), Bransonic ${ }^{\mathbb{R}}$ Ultrasonic Cleaner (Branson Ultrasonic Corporation, Danbury, CT, USA), and vortex-mixer (Scientific Industries Co., NY, USA) were used in this study.

\section{Animal experiments}

Male Sprague-Dawley rats weighing 270 to $300 \mathrm{~g}$ were purchased from Dae Han Laboratory Animal Research and Co. (Choongbuk, Korea), and were given access to normal standard chow diet (No. 322-7-1 Superfeed Co. Gangwon, Korea) and tap water ad libitum. Throughout the experiment, the animals were maintained at $22 \pm 2^{\circ} \mathrm{C}$, and $50-60 \%$ relative humidity, under a $12: 12 \mathrm{~h}$ light-dark cycle throughout the experiment. The animals were kept in these facilities for at least one week before the experimentation. The animal care committee of Chosun University approved the design and the conduct of this study.

\section{Oral and intravenous administration}

The rats were divided into seven groups of six animals in each group: (1) an oral control group, administered 40 $\mathrm{mg} / \mathrm{kg}$ paclitaxel orally; $(2,3,4)$ the oral pretreatment groups, administered oral apigenin $(0.4,2$ and $8 \mathrm{mg} / \mathrm{kg}) 30$ min prior to $40 \mathrm{mg} / \mathrm{kg}$ of oral paclitaxel, respectively; (5) an IV control group, administered $5 \mathrm{mg} / \mathrm{kg}$ of IV paclitaxel; $(6,7)$ the IV pretreatment groups, administered oral apigenin (2 and $8 \mathrm{mg} / \mathrm{kg}$ ) 30min prior to IV paclitaxel, respectively.

The rats were fasted for at least $24 \mathrm{~h}$ before the beginning of the experiments and had access to tap water ad libitum. Each animal was anaesthetized with ether and the 
right femoral artery was cannulated with polyethylene tubing for blood sampling.

Paclitaxel solution was prepared by dissolving paclitaxel in a mixture of Cremophor EL and ethanol (1:1, v/v, 4 $\mathrm{mg} / \mathrm{ml}$ for IV and $40 \mathrm{mg} / \mathrm{ml}$ for oral). Paclitaxel solution for IV was diluted with saline immediately prior to injection and injected through the femoral vein within $40 \mathrm{sec}(0.5 \mathrm{ml} / \mathrm{rat})$; the paclitaxel solution for oral administration was handmixed with hydroxypropyl methylcellulose powder $(10 \mathrm{mg} /$ $\mathrm{ml}$ ) to obtain a suspension and further diluted with distilled water (Gao et al., 2003) just before intragastric administration $(1.5 \mathrm{ml} / \mathrm{rat})$. The apigenin suspension was prepared by mixing in distilled water. Blood samples $(0.4 \mathrm{ml})$ were collected into heparinized tubes from the femoral artery at 0 (as a control), 0.017 (only for IV), 0.1, 0.25, 0.5, 1, $2,4,8,12$ and $24 \mathrm{~h}$ after the oral and IV administration of paclitaxel, and centrifuged at $13,000 \mathrm{rpm}$ for $5 \mathrm{~min}$. The plasmas were stored at $-40^{\circ} \mathrm{C}$ until HPLC analysis.

\section{HPLC analysis}

The plasma concentrations of paclitaxel were determined using the modified HPLC methods of Andreeva et al. (1997) and Lee et al. (1999). Briefly, a 0.2-ml plasma sample was mixed with $50 \mu \mathrm{l}$ of $4 \mu \mathrm{g} / \mathrm{ml}$ butyl paraben (internal standard), $0.8 \mathrm{ml}$ of tert-butylmethylether, and 0.6 $\mathrm{ml}$ of saturated dipotassium hydrogen phosphate solution in a $2.0-\mathrm{ml}$ polypropylene microtube. It was then vortexmixed vigorously for $0.5 \mathrm{~min}$ and centrifuged for $10 \mathrm{~min}$ at $13,000 \mathrm{rpm}$ and $0.6 \mathrm{ml}$ of the upper layer was carefully transferred to a clean microtube and evaporated under a gentle stream of nitrogen gas in a dry thermo bath at $38^{\circ} \mathrm{C}$. The resulting residue was dissolved in $0.2 \mathrm{ml}$ of $60 \%$ ace- tonitrile and washed with $1.0 \mathrm{ml}$ of $\mathrm{n}$-Hexane. A $50-\mu \mathrm{l}$ aliquot of the solution was injected for analysis.

The UV detector was operated at a wavelength of 227 $\mathrm{nm}$. A Symmetry ${ }^{\mathrm{R}} \mathrm{C}_{18}$ column $(4.6 \times 150 \mathrm{~mm}, 5 \mu \mathrm{m}$, Waters Co., Milford, MA, USA) was used at a temperature of $30^{\circ} \mathrm{C}$ set by the HPLC column temperature controller (Phenomenex Inc., CA, USA). The mobile phase consisted of acetonitrile/methanol/0.1\% H3PO4 (45: 12: 43, v/v/v) and the flow rate was maintained at $1.3 \mathrm{ml} / \mathrm{min}$. Chromatograms of blank plasma and plasma spiked with paclitaxel and butyl paraben are shown in Fig. 1. The peaks of paclitaxel and butyl paraben were distinctly separated; the retention times of paclitaxel and butyl paraben were 6.7 and $4.8 \mathrm{~min}$, respectively. The detection limit of paclitaxel was $10 \mathrm{ng} / \mathrm{ml}$. The coefficient of variation was below $14.2 \%$.

\section{CYP inhibition assay}

The assays of inhibition of human CYP3A4 enzyme activity were performed in multiwell plates using the CYP inhibition assay kit (GENTEST, Woburn, MA) as described previously (Crespi et al., 1997). Briefly, human CYP enzymes were obtained from baculovirus-infected insect cells. CYP substrates (7-BFC and 7-MFC for CYP3A4 and $2 \mathrm{C}$, respectively) were incubated with or without the test compounds in enzyme/substrate buffer consisting of 1 pmol of P450 enzyme and NADPH generating system (1.3 mM NADP, $3.54 \mathrm{mM}$ glucose 6-phosphate, $0.4 \mathrm{u} / \mathrm{ml}$ glucose 6-phosphate dehydrogenase and $3.3 \mathrm{mM} \mathrm{MgCl}_{2}$ ) in potassium phosphate buffer ( $\mathrm{pH} 7.4)$. Reactions were terminated by adding stop solution after the 45-min incubation. Metabolite concentrations were measured with a spectrofluorometer (Molecular Device, Sunnyvale, CA) at

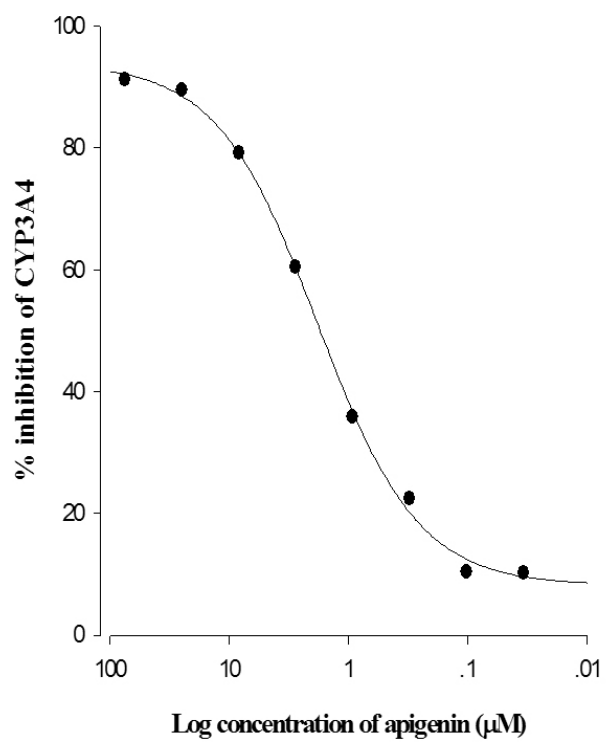

Log concentration of apigenin $(\mu \mathrm{M})$

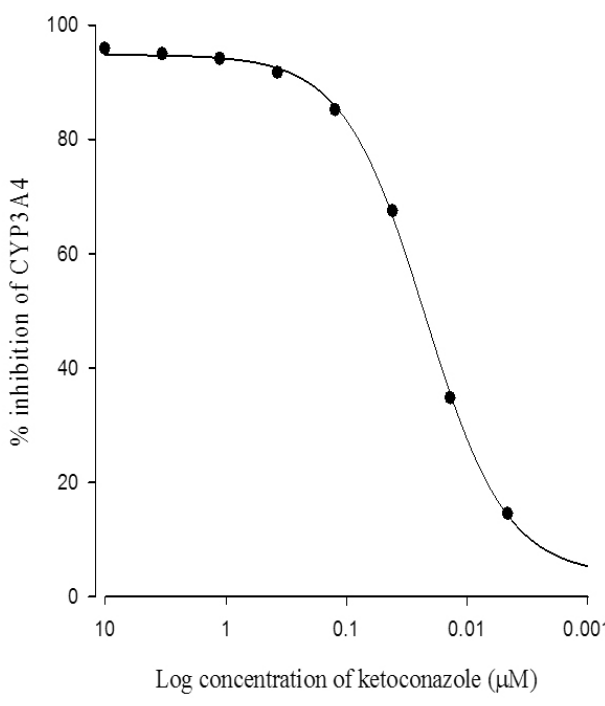

Fig. 1. Inhibitory effect of ketoconazole and apigenin on CYP3A4 activity. All experiments were performed in duplicate, and results are expressed as the percent of inhibition (The $\mathrm{IC}_{50}$ of apigenin; $1.8 \mu \mathrm{M})$. 
an excitation wavelength of $409 \mathrm{~nm}$ and an emission wavelength of $530 \mathrm{~nm}$. A positive control ( $1 \mu \mathrm{M}$ ketoconazole for CYP3A4) run on the same plate produced $99 \%$ inhibition. All experiments were performed in duplicate, and results are expressed as the percent of inhibition.

\section{Western blot analysis}

MCF-7 and MCF-7.ADR cells were collected and washed with cold phosphate-buffered saline (PBS). The harvested cells were then lysed on ice for $30 \mathrm{~min}$ in $100 \mu \mathrm{l}$ lysis buffer [120 mM NaCl, $40 \mathrm{mM}$ Tris (pH 8), 0.1\% NP40 (Nonidet P-40)] and centrifuged at 12,000 rpm for $30 \mathrm{~min}$. Supernatants were collected from the lysates and protein concentrations were determined using the BCA protein assay kit (Pierce, Rockford, IL). Aliquots of the lysates (30 $\mu \mathrm{g}$ of protein) were boiled for $5 \mathrm{~min}$ and electrophoresed on $10 \%$ SDS-polyacrylamide gels. Proteins in the gels were transferred onto nitrocellulose membranes, which were then incubated with P-gp antibody or actin antibody. The membranes were further incubated with secondary anti-mouse or anti-rabbit antibodies. Finally, protein bands were detected using an enhanced chemiluminescence Western blotting detection kit (Pierce Biotechnology, Rockford, IL).

\section{Rhodamine-123 retention assay}

MCF-7/ADR cells were seeded into 24-well plates at a seeding density of $10^{5}$ cells. At $80 \%$ confluence, the cells were incubated in FBS-free DMEM for $18 \mathrm{~h}$. The culture medium was changed to Hanks' balanced salt solution and the cells were incubated at $37^{\circ} \mathrm{C}$ for $30 \mathrm{~min}$. After incubation of the cells with $20 \mu \mathrm{M}$ rhodamine- 123 for $90 \mathrm{~min}$, the medium was completely removed. The cells were then washed three times with ice-cold phosphate buffer $(\mathrm{pH}$ 7.0) and lysed in lysis buffer. The rhodamine-123 fluorescence in the cell lysates was measured using excitation and emission wavelengths of 480 and $540 \mathrm{~nm}$, respectively. Fluorescence values were normalized to the total protein content of each sample and presented as the ratio to control.

\section{Pharmacokinetic analysis}

The plasma concentration data were analyzed by the non-compartmental method using WinNonlin software version 4.1 (Pharsight Co., Mountain View, CA, USA). The elimination rate constant $\left(\mathrm{K}_{\mathrm{el}}\right)$ was calculated by log-linear regression of paclitaxel concentration data during the elimination phase. The terminal half-life $\left(t_{1 / 2}\right)$ was calculated by $0.693 / \mathrm{K}_{\mathrm{el}}$. The peak plasma concentration $\left(\mathrm{C}_{\max }\right)$ and time to reach peak plasma concentration $\left(T_{\max }\right)$ of paclitaxel in plasma were obtained by visual inspection of the data from the concentration-time curve. The area under the plasma concentration-time curve $\left(\mathrm{AUC}_{0-\mathrm{t}}\right)$ from time zero to the time of last measured concentration $\left(\mathrm{C}_{\text {last }}\right)$ was calculated by the linear trapezoidal rule. The AUC zero to infinite $\left(A \cup C_{0-\infty}\right)$ was obtained by the addition of $A \mathrm{C}_{0-t}$ and the extrapolated area determined by $\mathrm{C}_{\text {last }} / \mathrm{K}_{\mathrm{el}}$. The total body clearance for the i.v. route $\left(C_{t}\right)$ was calculated from $D / A U C$, where $D$ is the dose of paclitaxel. The absolute bioavailability (A.B.) was calculated by $\mathrm{AUC}_{\text {oral }} / \mathrm{AUC}_{\mathrm{IV}} \times \mathrm{Dose}_{\mathrm{IV}} /$ Dose $_{\text {oral, }}$ and the relative bioavailability (R.B.) was calculated by $A U_{\text {Ccontrol }} / \mathrm{AUC}_{\text {with apigenin. }}$

\section{Statistical analysis}

Statistical analysis was conducted using one-way ANOVA followed by a posteriori testing with the Dunnett correction. Differences were considered to be significant at a level of $p<0.05$. All mean values are presented with their standard deviation (mean \pm S.D.).

\section{RESULTS}

\section{Inhibitory effect of apigenin on CYP3A4}

The inhibitory effect of apigenin on CYP3A4 activity is

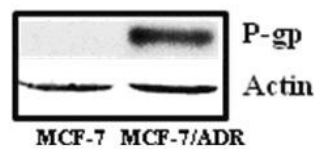

Fig. 2. P-gp expression in both MCF-7 and MCF-7/ADR cells. The protein levels of P-gp were determined by using P-gp specific antibody.

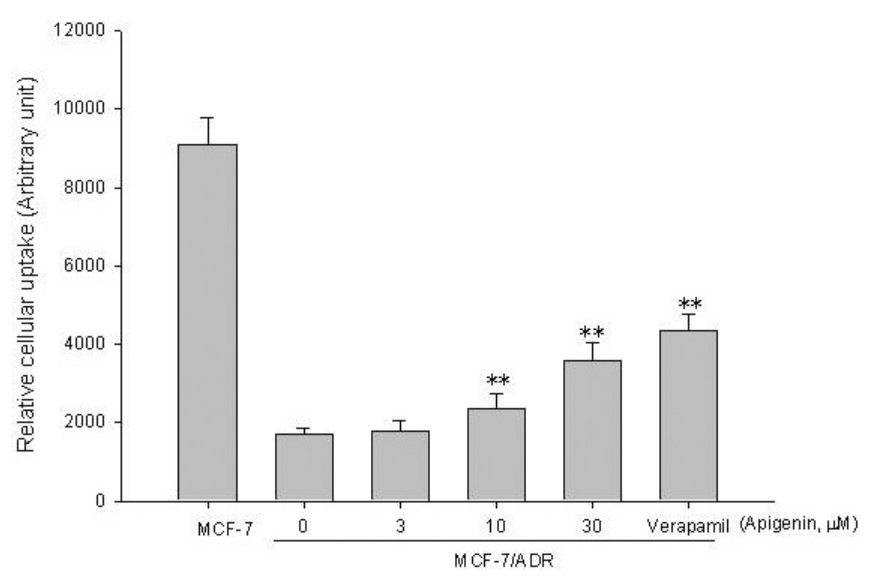

Fig. 3. Effect of apigenin on the cellular accumulation of rhodamine-123 in MCF-7 and MCF-7/ADR cells. Verapamil (100 $\mu \mathrm{M})$ was used as a positive control. Data represents mean \pm SD of 6 separate samples $\left({ }^{* *} p<0.01\right)$. 
shown in Fig. 1. Apigenin inhibited CYP3A4 enzyme activity. The $50 \%$ inhibition concentration $\left(\mathrm{IC}_{50}\right)$ value of apigenin on CYP3A4 activity was $1.8 \mu \mathrm{M}$; the value was higher than that of ketoconazole $(0.08 \mu \mathrm{M})$.

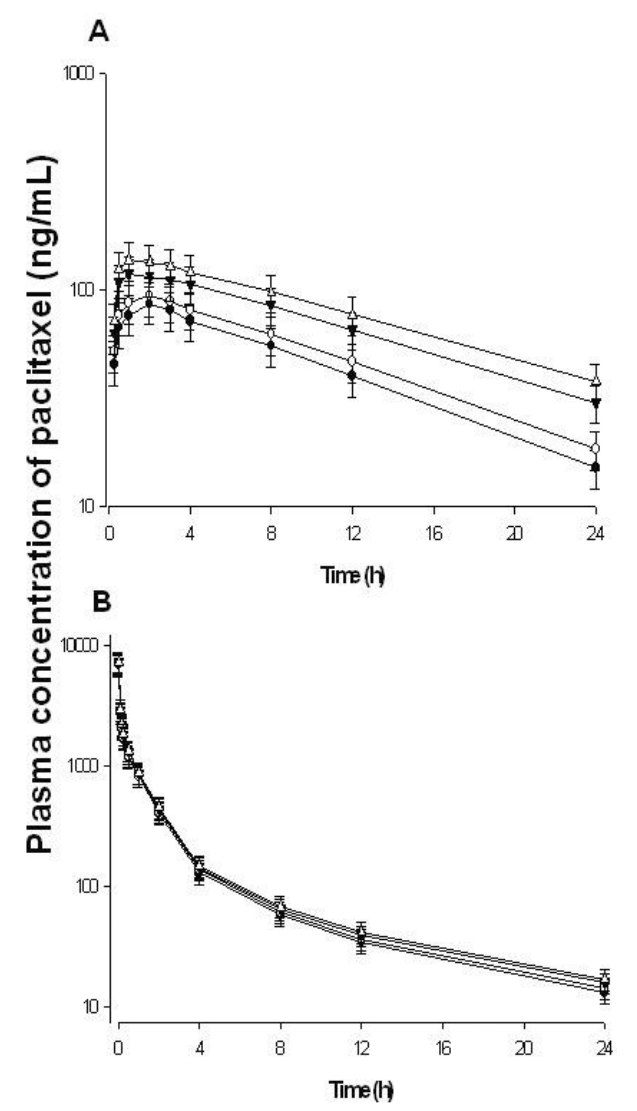

Fig. 4. Mean plasma concentration-time profiles of paclitaxel after $40 \mathrm{mg} / \mathrm{kg}$ oral (A) and $4 \mathrm{mg} / \mathrm{kg}$ intravenous (B) administration to rats in the presence and absence of apigenin $(0.4,2$ and $8 \mathrm{mg} / \mathrm{kg})(\mathrm{n}=6$, each). Bars represent the standard deviation; (O) oral administration of paclitaxel (40 mg/kg), ( $)$ the presence of $0.4 \mathrm{mg} / \mathrm{kg}$ of apigenin, $(\nabla)$ the presence of 2 $\mathrm{mg} / \mathrm{kg}$ of apigenin, $(\triangle)$ the presence of $8 \mathrm{mg} / \mathrm{kg}$ of apigenin.

\section{Western blot analysis}

When we compare P-gp protein expression in MCF-7 and MCF-7/ADR cells, the protein was only highly detected in MCF-7/ADR cells (Fig. 2).

\section{Rhodamine-123 retention assay}

As shown in Fig. 3, accumulation of rhodamine-123, a P-gp substrate, was raised in MCF-7/ADR cells over expressing P-gp compared to that in MCF-7 cells lacking P-gp. The concurrent use of apigenin enhanced the cellular uptake of rhodamine 123 and resulted in statistically significant $(p<0.01)$ increase over the concentration range of $10-30 \mu \mathrm{M}$ in a concentration-dependent manner. This result suggests that apigenin significantly inhibits P-gp activity.

\section{Effect of apigenin on the pharmacokinetics of oral paclitaxel}

The plasma concentration-time profiles of paclitaxel after oral $(40 \mathrm{mg} / \mathrm{kg})$ administration in the presence or absence of apigenin $(0.4,2$ and $8 \mathrm{mg} / \mathrm{kg}$ ) are illustrated in Fig. 4A, and the pharmacokinetic parameters for paclitaxel are shown in Table I. Compared to the oral control group, the presence of apigenin significantly $(p<0.05,2 \mathrm{mg} / \mathrm{kg}$; $p$ $<0.01,8 \mathrm{mg} / \mathrm{kg}$ ) increased the AUC of paclitaxel by $59-87 \%$. Apigenin also significantly $(p<0.05,2 \mathrm{mg} / \mathrm{kg} ; p$ $<0.01,8 \mathrm{mg} / \mathrm{kg}$ ) increased the $\mathrm{C}_{\max }$ of paclitaxel by $37.2-59.3 \%$. In addition, apigenin significantly increased the terminal half-life $\left(\mathrm{t}_{1 / 2}, p<0.05\right.$ by $\left.8,34.5 \%\right)$ of oral paclitaxel, but had no significant effect on the $\mathrm{T}_{\max }$ of paclitaxel. Consequently, the A.B. of paclitaxel was significantly ( $p$ $<0.05,2 \mathrm{mg} / \mathrm{kg} ; p<0.01,8 \mathrm{mg} / \mathrm{kg}$ ) increased by $5.9-7.0 \%$ compared with that in the control group (3.7\%), and the R.B. of paclitaxel was increased $1.14-$ to 1.87 -fold by apigenin.

Table I. Mean ( \pm S.D.) pharmacokinetic parameters of paclitaxel after oral administration $(40 \mathrm{mg} / \mathrm{kg})$ to rats without and with apigenin $(0.4,2$ and $8 \mathrm{mg} / \mathrm{kg})(\mathrm{n}=6$, each)

\begin{tabular}{lcccc}
\hline \multicolumn{1}{c}{ Parameter } & Control & \multicolumn{3}{c}{ Paclitaxel + Apigenin } \\
\cline { 3 - 5 } & & $0.4 \mathrm{mg} / \mathrm{kg}$ & $2 \mathrm{mg} / \mathrm{kg}$ & $8 \mathrm{mg} / \mathrm{kg}$ \\
\hline $\mathrm{AUC}_{0-\infty}(\mathrm{ng} \cdot \mathrm{h} / \mathrm{ml})$ & $1,048 \pm 223$ & $1,199 \pm 279$ & $1,663 \pm 412^{\mathrm{a}}$ & $1,958 \pm 483^{\mathrm{b}}$ \\
$\mathrm{C}_{\max }(\mathrm{ng} \cdot \mathrm{ml})$ & $86 \pm 18.1$ & $94 \pm 18.7$ & $118 \pm 23.6^{\mathrm{a}}$ & $137 \pm 27.9^{\mathrm{b}}$ \\
$\mathrm{T}_{\max }(\mathrm{h})$ & $1.67 \pm 0.51$ & $1.67 \pm 0.52$ & $1.33 \pm 0.52$ & $1.33 \pm 0.52$ \\
$\mathrm{t}_{1 / 2}(\mathrm{~h})$ & $8.7 \pm 1.70$ & $9.1 \pm 1.87$ & $10.7 \pm 2.51$ & $11.7 \pm 2.81^{\mathrm{a}}$ \\
$\mathrm{A} . \mathrm{B}(\%)$ & $3.7 \pm 1.01$ & $4.3 \pm 1.11$ & $5.9 \pm 1.24^{\mathrm{a}}$ & $7.0 \pm 1.42^{\mathrm{b}}$ \\
$\mathrm{R} . \mathrm{B} .(\%)$ & 100 & 114 & 159 & 187 \\
\hline
\end{tabular}

${ }^{a} p<0.05,{ }^{b} p<0.01$, significantly different from the control. $\mathrm{AUC}_{0-\infty}$ : area under the plasma concentration-time curve from $0 \mathrm{~h}$ to infinity, $\mathrm{C}_{\max }$ : peak plasma concentration, $T_{\max }$ : time to reach $C_{\max }, t_{1 / 2}$ : terminal half-life, A.B.: absolute bioavailability, R.B.: relative bioavailability. 
Table II. Mean ( \pm S.D.) pharmacokinetic parameters of paclitaxel after intravenous administration $(5 \mathrm{mg} / \mathrm{kg})$ to rats without and with apigenin $(0.4,2$ and $8 \mathrm{mg} / \mathrm{kg})(\mathrm{n}=6$, each)

\begin{tabular}{lcccc}
\hline \multirow{2}{*}{ Parameter } & Control & \multicolumn{3}{c}{ Paclitaxel + Apigenin } \\
\cline { 2 - 5 } & & $0.4 \mathrm{mg} / \mathrm{kg}$ & $2 \mathrm{mg} / \mathrm{kg}$ & $8 \mathrm{mg} / \mathrm{kg}$ \\
\hline $\mathrm{AUC} \mathrm{C}_{0-\infty}(\mathrm{ng} \cdot \mathrm{h} / \mathrm{ml})$ & $3,522 \pm 734$ & $3,667 \pm 763$ & $3,840 \pm 791$ & $3,949 \pm 808$ \\
$\mathrm{CL}_{\mathrm{t}}(\mathrm{ml} / \mathrm{min} / \mathrm{kg})$ & $18.2 \pm 4.2$ & $17.4 \pm 4.0$ & $16.6 \pm 3.8$ & $16.1 \pm 3.7$ \\
$\mathrm{t}_{1 / 2}(\mathrm{~h})$ & $7.7 \pm 1.7$ & $7.8 \pm 1.9$ & $8.2 \pm 2.0$ & $8.3 \pm 2.2$ \\
R.B. $(\%)$ & 100 & 104 & 109 & 112 \\
\hline
\end{tabular}

$\mathrm{AUC}_{0-\infty}$ : area under the plasma concentration-time curve from $0 \mathrm{~h}$ to infinity, $\mathrm{t}_{1 / 2}$ : terminal half-life, $\mathrm{CL}_{\mathrm{t}}$ : total body clearance, $\mathrm{R} . \mathrm{B} .:$ relative bioavailability.

\section{Effect of apigenin on the pharmacokinetics of IV paclitaxel}

The plasma concentration-time profiles of paclitaxel following IV administration of paclitaxel $(5 \mathrm{mg} / \mathrm{kg})$ in the presence of apigenin are shown in Fig. $4 \mathrm{~B}$, and the pharmacokinetic parameters are summarized in Table II. After administration of paclitaxel with apigenin, the total body clearance $(\mathrm{CL})$ values of paclitaxel tended to decrease; the bioavailability (AUC) of paclitaxel consequently increased, but was not statistically significant compared to that in the control. The $t_{1 / 2}$ of paclitaxel was also increased, but this increase was not significant. The pharmacokinetics of intravenous paclitaxel were not affected by the concurrent use of apigenin in contrast to those of oral paclitaxel. Accordingly, the enhanced oral bioavailability in the presence of apigenin, while there was no significant change in the pharmacokinetics of intravenous paclitaxel, may be mainly due to the increased intestinal absorption via P-gp inhibition by apigenin rather than to the reduced renal or hepatic elimination of paclitaxel.

These results suggest that the increase in the oral bioavailability was mainly attributed to enhanced absorption in the gastrointestinal tract via the inhibition of both P-gp and CYP3A by apigenin.

\section{DISCUSSION}

The low bioavailability of paclitaxel following oral administration would result from metabolism by the enzymes or counter-transport processes due to P-gp in the intestinal wall. Paclitaxel is reportedly metabolized by CYP3A4 and CYP2C8 in both liver and small intestine (Harris et al., 1994; Rahman et al., 1994; Sonnichsen et al., 1995), and it is a substrate for the efflux transporters such as P-gp (Sparreboom et al., 1997). Inhibition of the metabolic enzymes and the efflux transporters must be the contributors to improve the oral bioavailability of paclitaxel. Woo et al. (2003) have demonstrated that about $54 \%$ of oral dose of a paclitaxel is extruded to the gut lumen by P-gp, and $5 \%$ of paclitaxel dose is eliminated by intestinal and first-pass metabolism. Previous reports also indicated that the inhibition of both P-gp and CYP3A4 increased bioavailability of paclitaxel in rats by only $20 \%$ in comparison to inhibition of only P-gp, and thus intestinal and hepatic metabolism seem to contribute relatively less to paclitaxel absorption (Woo et al., 2003).

The P-gp co-localized with CYP3A4 (Cummins et al., 2002) mainly provide a synergistic function in regulating the bioavailability of many orally administered compounds. The inhibitory effect of apigenin against CYP3A4-mediated metabolism was confirmed by the use of recombinant CYP3A4 enzyme. As shown in Fig. 1, apigenin inhibited CYP3A4-mediated metabolism with $\mathrm{IC}_{50}$ of $1.8 \mu \mathrm{M}$. Furthermore, the cell-based assay using rhodamine-123 indicated that apigenin $(10-30 \mu \mathrm{M})$ significantly $(p<0.01)$ inhibited P-gp-mediated drug efflux (Fig. 3). These results are coincident with previous studies (Nguyen et al., 2003; Kimura et al., 2010), and suggest that apigenin might improve the bioavailability of paclitaxel, a dual substrate of CYP3A4 and P-gp. Therefore, the pharmacokinetic characteristics of paclitaxel were evaluated with apigenin in rats. As CYP3A9 expressed in rat is corresponding to the ortholog of CYP3A4 in human (Kelly et al., 1999) and human CYP2C9 and 3A4 and rat CYP2C11 and 3A1 have 77 and $73 \%$, respectively, protein homology (Lewis, 1996). Rats were selected as an animal model in this study to evaluate the potential pharmacokinetic interactions mediated by CYP3A4, although there should be some difference in enzyme activity between rat and human (Cao et al., 2006). In this study, apigenin increased the AUC and $\mathrm{C}_{\max }$ of oral paclitaxel since apigenin acts as an inhibitor of CYP3A4 and P-gp. The enhanced oral bioavailability of paclitaxel might contribute to the inhibition of paclitaxel metabolism by CYP3A4 both in the liver and intestine. These results were consistent with report by Choi and Shin (2005), in which naringin significantly increased the AUC and $\mathrm{C}_{\max }$ of paclitaxel, a substrate for P-gp and CYP3A4. It is also supported by the findings that quercetin, as a P-gp 
and CYP3A4 inhibitor, enhanced the oral bioavailability of paclitaxel (Critchfield et al., 1994), and genistein, another P-gp and CYP3A4 inhibitor, enhanced the oral bioavailability of paclitaxel administered orally or intravenously in rats (Li and Choi, 2007). In addition, cyclosporine A, another P-gp and CYP3A4 inhibitor, significantly increased the bioavailability of oral paclitaxel in humans (Meerum Terwogt et al., 1999).

After intravenous administration of paclitaxel with apigenin, the CLt of paclitaxel tended to be decreased and the AUC of paclitaxel was increased, but these values were not statistically different from those in the control. These results were consistent with the report by Choi et al. (2006), in that morin did not significantly increase the AUC of intravenous paclitaxel, a substrate for P-gp and CYP $3 \mathrm{~A} 4$ in rats. The pharmacokinetics of intravenous paclitaxel were not affected by the concurrent use of apigenin in contrast to those of oral paclitaxel. Accordingly, the enhanced oral bioavailability, while there was no significant change in the pharmacokinetics of intravenous paclitaxel, may be mainly due to increased intestinal absorption via $\mathrm{P}$-gp inhibition by apigenin rather than to reduced hepatic and renal elimination of paclitaxel.

These results suggest that the increase in the oral bioavailability of paclitaxel might be mainly attributed to enhanced absorption in the gastrointestinal tract via the inhibition of P-gp and the reduced first-pass metabolism of paclitaxel due to inhibition of the CYP3A subfamily in the small intestine and/or in the liver by apigenin. Therefore, the concurrent use of apigenin may provide a beneficial effect for anticancer therapy as the oral drug delivery of paclitaxel in rats.

\section{ACKNOWLEDGMENTS}

The present study was supported by grants from the Clinical Medicine Research Institute at Chosun University Hospital (2007).

\section{REFERENCES}

Andreeva, M., Niedmann, P. D., Binder, L., Armstrong, V. W., Meden, H., Binder, M. and Oellerich, M. (1997). A simple and reliable reverse-phase high-performance liquid chromatographic procedure for determination of paclitaxel (taxol) in human serum. Ther. Drug. Monit. 19, 327-332.

Berg, S. L., Tolcher, A., O'Shaughnessy, J. A., Denicoff, A. M., Noone, M., Ognibene, F. P., Cowan, K. H. and Balis, F. M. (1995). Effect of R-verapamil on the pharmacokinetics of paclitaxel in women with breast cancer. J. Clin. Oncol. 13, 2039-2042.

Cao, X., Gibbs, S. T., Fang, L., Miller, H. A., Landowski, C. P.,
Shin, H. C., Lennernas, H., Zhong, Y., Amidon, G. L., Yu, L. $X$. and Sun, D. (2006). Why is it challenging to predict intestinal drug absorption and oral bioavailability in human using rat model. Pharm. Res. 23, 1675-1686.

Choi, B. C., Choi, J. S. and Han, H. K. (2006). Altered pharmacokinetics of paclitaxel by the concomitant use of morin in rat. Int. J. Pharm. 323, 81-85.

Choi, J. S., Kim, Y. C. and Jo, B. W. (2004). Enhanced paclitaxel bioavailability after oral administration of paclitaxel or prodrug to rats pretreated with quercetin. Eur. J. Pharm. Biopharm. 57, 313-318.

Choi, J. S. and Li, X. (2005). The effect of verapamil on the pharmacokinetics of paclitaxel in rats. Eur. J. Pharm. Sci. 24, 95-100.

Choi, J. S. and Shin, S. C. (2005). Enhanced paclitaxel bioavailability after oral coadministration of paclitaxel prodrug with naringin to rat. Int. J. Pharm. 292, 149-156.

Choi, S. U., Lee, B. H., Kim, K. H., Choi, E. J., Park, S. H., Shin, H. S., Yoo, S. E., Jung, N. P. and Lee, C. O. (1997). Novel multidrug-resistance modulators, KR-30026 and KR-30031, in cancer cells. Anticancer. Res. 17, 4577-4582.

Chuang, C. M., Monie, A., Wu, A. and Hung, C. F. (2009). Combination of apigenin treatment with therapeutic HPV DNA vaccination generates enhanced therapeutic antitumor effects. J. Biomed. Sci. 27, 49-60.

Crespi, C. L., Miller, V. P. and Penman, B. W. (1997). Microtiter plate assays for inhibition of human, drug-metabolizing cytochromes P450. Anal. Biochem. 248, 188-190.

Critchfield, J. W., Welsh, C. J., Phang, J. M. and Yeh, G. C. (1994). Modulation of adriamycin accumulation and efflux by flavonoids in HCT-15 colon cells. Activation of P-glycoprotein as a putative mechanism. Biochem. Pharmacol. 48, 1437-1445.

Cummins, C. L., Jacobsen, W. and Benet, L. Z. (2002). Unmasking the dynamic interplay between intestinal P-glycoprotein and CYP3A4. J. Pharmacol. Exp. Ther. 300, 1036-1045.

Dixon, R. A. and Steele, C. L. (1999). Flavonoids and isoflavonoids - a gold mine for metabolic engineering. Trends. Plant Sci. 4, 394-400.

Fukuda, K., Ohta, T., Oshima, Y., Ohashi, N., Yoshikawa, M. and Yamazoe, Y. (1997). Specific CYP3A4 inhibitors in grapefruit juice: furocoumarin dimers as components of drug interaction. Pharmacogenetics. 7, 391-396.

Galati, G., Moridani, M. Y., Chan, T. S. and O'brien, P. J. (2001). Peroxidative metabolism of apigenin and naringenin versus luteolin and quercetin: glutathione oxidation and conjugation. Free. Radical. Biology \& Medicine. 30, 370-382.

Gao, P., Rush, B. D., Pfund, W. P., Huang, T., Bauer, J. M., Morozowich, W., Kuo, M. S. and Hageman, M. J. (2003). Development of a supersaturable SEDDS (S-SEDDS) formulation of paclitaxel with improved oral bioavailability. $J$. Pharm. Sci. 92, 2386-2398.

Gates, M. A., Vitonis, A. F., Tworoger, S. S., Rosner, B., Titus-Ernstoff, L., Hankinson, S. E. and Cramer, D. W. (2009). Flavonoid intake and ovarian cancer risk in a population-based case-control study. Int. J. Cancer. 124, 1918-1925.

Harris, J. W., Rahman, A., Kim, B. R., Guengerich, F. P. and Collins, J. M. (1994). Metabolism of taxol by human hepatic microsomes and liver slices: participation of cytochrome 
P450 3A4 and an unknown P450 enzyme. Cancer Res. 54, 4026-4035.

Ho, P. C., Saville, D. J. and Wanwimolruk, S. (2001). Inhibition of human CYP3A4 activity by grapefruit flavonoids, furanocoumarins and related compounds. J. Pharm. Pharm. Sci. 4, 217-227.

Jeong, G. S., Lee, S. H., Jeong, S. N., Kim, Y. C. and Kim, E. C. (2009). Anti-inflammatory effects of apigenin on nicotineand lipopolysaccharide-stimulated human periodontal ligament cells via heme oxygenase-1. Int. Immunopharmacol. 9, 1374-1380.

Kelly, P. A., Wang, H., Napoli, K. L., Kahan, B. D. and Strobel, H. W. (1999). Metabolism of cyclosporine by cytochromes P450 3A9 and 3A4. Eur. J. Drug. Metab. Pharmacokinet. 24, 321-328.

Kimura, Y., Ito, H., Ohnishi, R. and Hatano, T. (2010). Inhibitory effects of polyphenols on human cytochrome P450 3A4 and 2C9 activity. Food. Chem. Toxicol. 48, 429-435.

Lee, S. H., Yoo, S. D. and Lee, K. H. (1999). Rapid and sensitive determination of paclitaxel in mouse plasma by high-performance liquid chromatography. J. Chomatogr. B. Biomed. Sci. 724, 357-363.

Lewis, D. F. V. (1996). Cytochrome P450. Substrate specificity and metabolism. In Cytochromes P450. Structure, Function, and Mechanism (D. F. V. Lewis, Ed.), pp. 122-123. Taylor \& Francis, Bristol.

Li, X. and Choi J. S. (2007). Effect of genistein on the pharmacokinetics of paclitaxel administered orally or intravenously in rats. Int. J. Pharm. 337, 188-193.

Meerum Terwogt, J. M., Malingre, M. M., Beijnen, J. H., ten Bokkel Huinink, W. W., Rosing, H., Koopman, F. J., van Tellingen, O., Swart, M. and Schellens, J. H. (1999). Coadministration of oral cyclosporin A enables oral therapy with paclitaxel. Clin. Cancer Res. 5, 3379-3384.

Nafisi, S., Hashemi, M. and Rajabi, M. (2008). DNA Adducts with Antioxidant Flavonoids: Morin, Apigenin, and Naringin. DNA and Cell Biology 27, 1-10.

Nguyen, H., Zhang, S. and Morris, M. E. (2003). Effect of flavonoids on MRP1-mediated transport in Panc-1 cells. J.
Pharm. Sci. 92, 250-257.

Rahman, A., Korzekwa, K. R., Grogan, J., Gonzalez, F. J. and Harris, J. W. (1994). Selective biotransformation of taxol to 6 alpha-hydroxytaxol by human cytochrome P450 2C8. Cancer Res. 54, 5543-5546.

Rowinsky, E. K., Eisenhauer, E. A., Chaudhry, V., Arbuck, S. G. and Donehower, R. C. (1993).Clinical toxicities encountered with paclitaxel (Taxol). Semin. Oncol. 20, 1-15.

Sonnichsen, D. S., Liu, Q., Schuetz, E. G., Schuetz, J. D., Pappo, A. and Relling, M. V. (1995). Variability in human cytochrome P450 paclitaxel metabolism. J. Pharmacol. Exp. Ther. 27, 566-575.

Sparreboom, A., van Asperen, J., Mayer, U., Schinkel, A. H., Smit, J. W., Meijer, D. K., Borst, P., Nooijen, W. J., Beijnen, J. H. and van Tellingen, O. (1997). Limited oral bioavailability and active epithelial excretion of paclitaxel (Taxol) caused by P-glycoprotein in the intestine. Proc. Natl. Acad. Sci. USA. 4, 2031-2035.

van Asperen, J., van Tellingen, O., van der Valk, M. A., Rozenhart, M. and Beijnen, J. H. (1998). Enhanced oral absorption and decreased elimination of paclitaxel in mice cotreated with cyclosporine A. Clin. Cancer Res. 4, 22932297.

Walle, T., Walle, U. K., Kuma, G. N. and Bhalla, K. N. (1995). Taxol metabolism and disposition in cancer patients. Drug Metab. Disp. 23, 506-512.

Wani, M. C., Taylor, H. L., Wall, M. E., Coggon, P. and McPhail, A. T. (1971). Plant antitumor agnets. VI. The isolation and structure of taxol, a novel antileukemic and antitumor agent from Taxus brevifolia. J. Am. Chem. Soc. 93, 2325-2327.

Woo, J. S., Lee, C. H., Shim, C. K. and Hwang, S. J. (2003) Enhanced oral bioavailability of paclitaxel by coadministration of the P-gp inhibitor KR30031. Pharm. Res. 20, 24-30.

Yin, Y., Gong, F. Y., Wu, X. X., Sun, Y., Li, Y. H., Chen, T. and $\mathrm{Xu}, \mathrm{Q}$. (2008). Anti-inflammatory and immunosuppressive effect of flavones isolated from Artemisia vestita. J. Ethnopharmacol. 120, 1-6. 